\title{
PERAN GUIDED INQUIRY DALAM PEMAHAMAN KONSEP SISWA KELAS VIII PADA PEMBELAJARAN TEOREMA PYTHAGORAS
}

\author{
Hanifah Oktinasari, Rully Charitas Indra Prahmana \\ Universitas Ahmad Dahlan, Jl. Pramuka 42, Pandeyan, Umbulharjo, Yogyakarta, Indonesia \\ E-mail: rully.indra@mpmat.uad.ac.id
}

\begin{abstract}
Abstrak
Penelitian ini bertujuan untuk mengetahui peran guided inquiry pada pemahaman konsep siswa dalam pembelajaran Teorema Pythagoras, melalui Lembar Aktivitas Siswa berbasis model pembelajaran guided inquiry. Penelitian ini menggunakan metode penelitian deskriptif kualitatif, yang dilaksanakan di kelas VIII D SMP Muhammadiyah 1 Gamping. Teknik pengumpulan data yang digunakan adalah dokumentasi, observasi, dan tes tertulis. Data yang diperoleh dalam penelitian ini dianalisis menggunakan teknik triangulasi data. Hasil penelitian menunjukkan bahwa Guided Inquiry berperan dalam membantu siswa untuk memahami konsep rumus teorema Pythagoras, melalui beberapa tahapan pembelajaran. Pada pembelajaran yang menggunakan guided inquiry, siswa dibimbing secara terstruktur untuk memahami rumus teorema Pythagoras dengan menemukan sendiri dan difasilitasi oleh guru. Selain itu, hasil belajar siswa menunjukkan bahwa nilai rata-rata yang diperoleh diatas nilai Kriteria Ketuntasan Minimal untuk mata pelajaran matematika sebesar 65 .
\end{abstract}

Kata Kunci: Guided Inquiry, Kemampuan Pemahaman Konsep, Teorema Pythagoras

\begin{abstract}
This study aims to determine the role of Guided Inquiry in understanding students' concepts in learning the Pythagorean theorem, through student worksheet-based guided inquiry learning models. This study uses descriptive qualitative research methods, which were carried out in class VIII D at SMP Muhammadiyah 1 Gamping. Data collection techniques used were documentation, observation, and written tests. Data obtained in this study were analyzed using data triangulation techniques. The results showed that the Guided Inquiry had a role in helping students to understand the concept of the Pythagorean theorem formula, through several stages of learning. In learning that uses guided inquiry, students can understand the Pythagorean theorem formula by finding it on their own and being facilitated by the teacher. Also, student learning outcomes indicate that the average value obtained by students is above the Minimum Mastery Criteria score for mathematics subjects of 65.
\end{abstract}

Keywords: Guided Inquiry, Conceptual Understanding Ability, Pythagoras Theorem

\section{PENDAHULUAN}

Pemahaman konsep matematika dipandang sebagai suatu kemampuan siswa dalam menjelaskan suatu konsep, sehingga siswa dapat mengomunikasikan kembali apa yang telah mereka pelajari dan menggunakan konsep tersebut untuk menyelesaikan permasalahan yang berbeda (Purwanti, Pratiwi, \& Rinaldi, 2016; Pratiwi, 2016). Selanjutnya, siswa dapat dikatakan mempunyai kemampuan pemahaman konsep 
matematika, jika dapat menyelesaikan suatu permasalahan dengan perhitungan sederhana dan dapat mengubah bentuk permasalahan ke bentuk model matematika dalam pembelajaran (Mawaddah \& Maryanti, 2016; Ramadhani \& Prahmana, 2019). Oleh karena itu, pemahaman konsep merupakan salah satu bentuk kemampuan yang penting untuk dikuasai siswa dalam pembelajaran matematika.

Namun, hasil observasi yang dilakukan sebelum melaksanakan penelitian di SMP Muhammadiyah 1 Gamping, menunjukkan bahwa lebih dari 50\% siswa merasa kesulitan dalam memahami konsep matematika, yang mengindikasikan bahwa kemampuan pemahamannya masih rendah. Banyak siswa yang lupa, bahkan tidak ingat sama sekali tentang konsep-konsep yang telah dipelajari pada kelas VII. Hal ini sejalan dengan hasil penelitian sejumlah peneliti yang menyatakan bahwa sejumlah siswa memiliki pemahaman matematis yang rendah dikarenakan mereka lebih fokus pada hafalan daripada memahami materi yang diberikan oleh guru di kelas (Hendriana, 2014; Lestari, 2015; Masjudin, 2017).

Selanjutnya, hasil wawancara yang dilakukan dengan salah satu guru Matematika di SMP Muhammadiyah 1 Gamping, menginformasikan bahwa salah satu faktor yang mempengaruhi siswa kelas VIII melakukan kesalahan saat menyelesaikan permasalahan yaitu siswa terbiasa menghafalkan rumus dan contoh soal, sehingga jika diberikan soal dalam bentuk yang lain, mereka akan kesulitan dalam menyelesaikannya. Selain itu, guru Matematika disana menggunakan pembelajaran konvensional (ceramah) dalam kegiatan belajar mengajar dan mengatakan bahwa salah satu materi matematika yang konsepnya sulit dipahami oleh siswa adalah Teorema Pythagoras.

Teorema Pythagoras merupakan salah satu materi Matematika yang terdapat pada kelas VIII SMP (Peraturan Menteri Pendidikan dan Kebudayaan Nomor 24 Tahun 2016). Selanjutnya, Rahma (2019) menyatakan bahwa teorema Pythagoras merupakan hubungan antara sisi miring kuadrat dengan jumlah kuadrat sisi-sisi lainnya, yang khusus terjadi pada suatu segitiga siku-siku. Di sisi lain, materi Teorema Pythagoras termasuk salah satu materi yang sukar bagi siswa kelas VIII SMP, karena banyak siswa yang tidak memahami konsep dari Teorema Pythagoras yang berakibat pada hasil belajar yang didapat belum memuaskan (Akbar, Rohaeti, \& Senjayawati, 2019). Oleh karena itu, agar hasil belajar siswa pada materi Teorema Pythagoras memuaskan, perlu adanya pemahaman konsep bagi siswa dengan menggunakan model pembelajaran yang berbeda. 
Salah satu model pembelajaran yang mampu menumbuhkan kemampuan pemahaman matematis siswa adalah model pembelajaran guided inquiry (Ulfah \& Prahmana, 2018; Zamnah \& Ruswana, 2018; Rahmasantika \& Prahmana, 2019). Model pembelajaran guided inquiry merupakan model pembelajaran yang mengharuskan siswa mencari, mengumpulkan data, dan menggunakan berbagai macam informasi serta ide dibawah pengawasan guru, sehingga menemukan konsep pada suatu materi (Murnaka \& Dewi, 2018; Gunur, Lalus, \& Ali, 2019). Selain itu, Badjeber dan Fatimah (2015) menjelaskan bahwa guided inquiry dapat mendorong siswa untuk menemukan prinsip, mencari masalah, dan memecahkan masalah yang diberikan. Oleh karena itu, peneliti tertarik untuk menggunakan model pembelajaran Guided Inquiry dalam upaya membantu pemahaman konsep matematika siswa. Selanjutnya, proses pembelajaran dideskripsikan untuk melihat peran model pembelajaran tersebut dalam membantu siswa untuk memahami konsep rumus Teorema Pythagoras.

\section{METODE PENELITIAN}

Penelitian ini merupakan penelitian deskriptif kualitatif yang mendeskripsikan proses pembelajaran rumus teorema Pythagoras menggunakan model pembelajaran guided inquiry. Prosedur penelitian ini meliputi tahap persiapan, tahap pelaksanaan, dan analisis data. Penelitian dilakukan di SMP Muhammadiyah 1 Gamping, Yogyakarta pada semester genap tahun ajaran 2019/2020. Subjek penelitian dalam penelitian ini adalah siswa kelas VIII D yang terdiri dari 32 siswa. Teknik pengumpulan data yang digunakan berupa dokumentasi (foto dan video), observasi, dan tes tertulis. Data foto, video, dan hasil observasi yang diperoleh dari hasil dokumentasi dan observasi dianalisis menggunakan teknik triangulasi data untuk menggambarkan serta mendeskripsikan proses pembelajaran, sehingga dapat melihat peran dari model pembelajaran yang diberikan dan dapat melihat bagaimana pemahaman konsep siswa pada materi teorema pythagoras.

\section{HASIL DAN PEMBAHASAN}

Penelitian ini terbagi dalam sejumlah aktivitas. Siswa bekerja secara berkelompok untuk menyelesaikan setiap aktivitas yang diberikan. Terdapat 7 kelompok yang masing- 
masing kelompok, terdiri dari 4 atau 5 orang. Berikut deskripsi dari setiap aktivitas yang telah dilaksanakan.

\section{Memeriksa kebenaran Teorema Pythagoras menggunakan gambar}

Kegiatan ini bertujuan agar siswa dapat memahami bahwa pembuktian rumus teorema Pythagoras erat kaitannya dengan segitiga siku-siku dan luas persegi, yang dapat dilihat melalui aktivitas menggambar dan menghubungkan persegi satuan. Selain itu, siswa dapat memahami konsep dari rumus teorema Pythagoras berdasarkan aktivitas yang diberikan.

Salah satu kelompok yaitu kelompok 4 berhasil menempelkan persegi dan menjawab pertanyaan pada kegiatan 1, sesuai dengan langkah-langkah kegiatan yang diberikan. Setelah menghitung luas tiap persegi secara bersama-sama, mereka menyimpulkan, bahwa luas persegi yang terbesar sama dengan jumlah dua luas persegi yang kecil. Setelah mendapatkan jawaban tersebut, mereka menyimpulkan hubungan antara $\mathrm{a}, \mathrm{b}$ dan $\mathrm{c}$ adalah $\mathrm{c}^{2}=\mathrm{a}^{2}+\mathrm{b}^{2}$, seperti terlihat pada Gambar 1 .
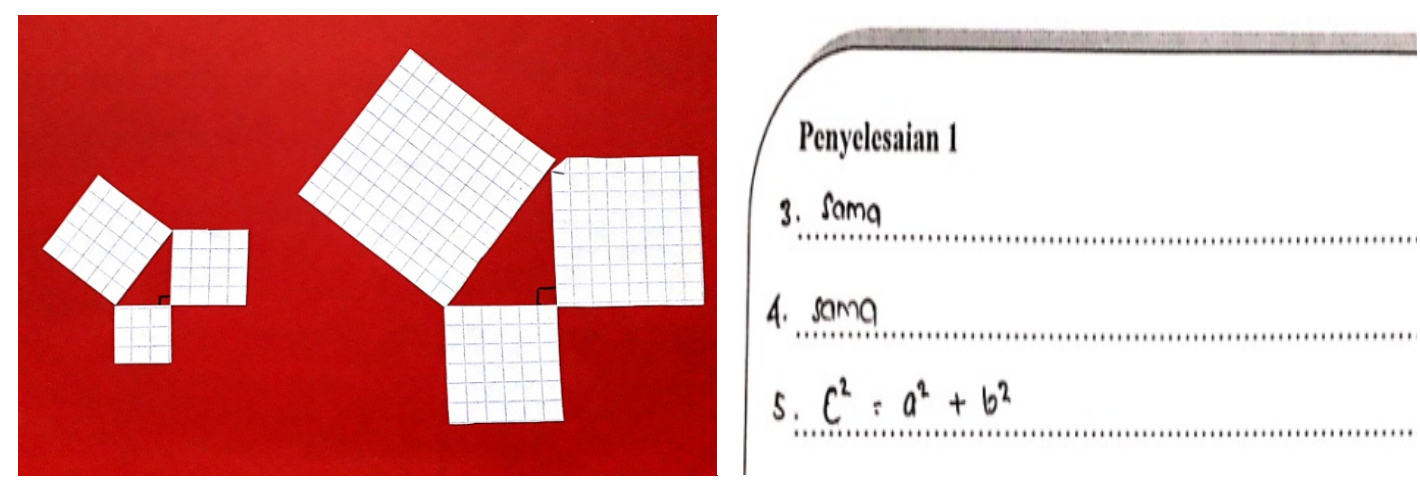

Gambar 1. Penyelesaian Kegiatan 1 Kelompok 4

\section{Menentukan panjang sisi segitiga siku-siku, jika panjang dua sisi diketahui melalui gambar}

Kegiatan ini bertujuan agar siswa dapat menentukan panjang salah satu sisi segitiga siku-siku, jika panjang dua sisi diketahui melalui gambar. Selanjutnya, siswa dapat menentukan hubungan antara ketiga sisi untuk merumuskan Teorema Pythagoras.

Kelompok 2 menggambar ketiga segitiga dengan baik, sesuai instruksi pada lembar kerja yang disediakan. Mereka menggambar satu persatu menggunakan penggaris dan mengukur panjang AC menggunakan penggaris tanpa melakukan perhitungan.

Setelah dilakukan pengukuran pada gambar, diperoleh panjang AC yang pertama 
yaitu 13, panjang AC yang kedua yaitu 14,5 dan panjang AC yang ketiga yaitu 15. Pada kolom $\mathrm{AB}^{2}, \mathrm{BC}^{2}$, dan $\mathrm{AC}^{2}$ mereka melakukan perhitungan kuadrat dari panjang yang sudah diketahui yaitu pada kolom $\mathrm{AB}, \mathrm{BC}$ dan $\mathrm{AC}$ dengan benar. Selanjutnya mereka menarik kesimpulan berdasarkan tabel yang telah diisi yaitu sisi AC lebih panjang dari sisi lainnya, seperti tampak pada Gambar 2.
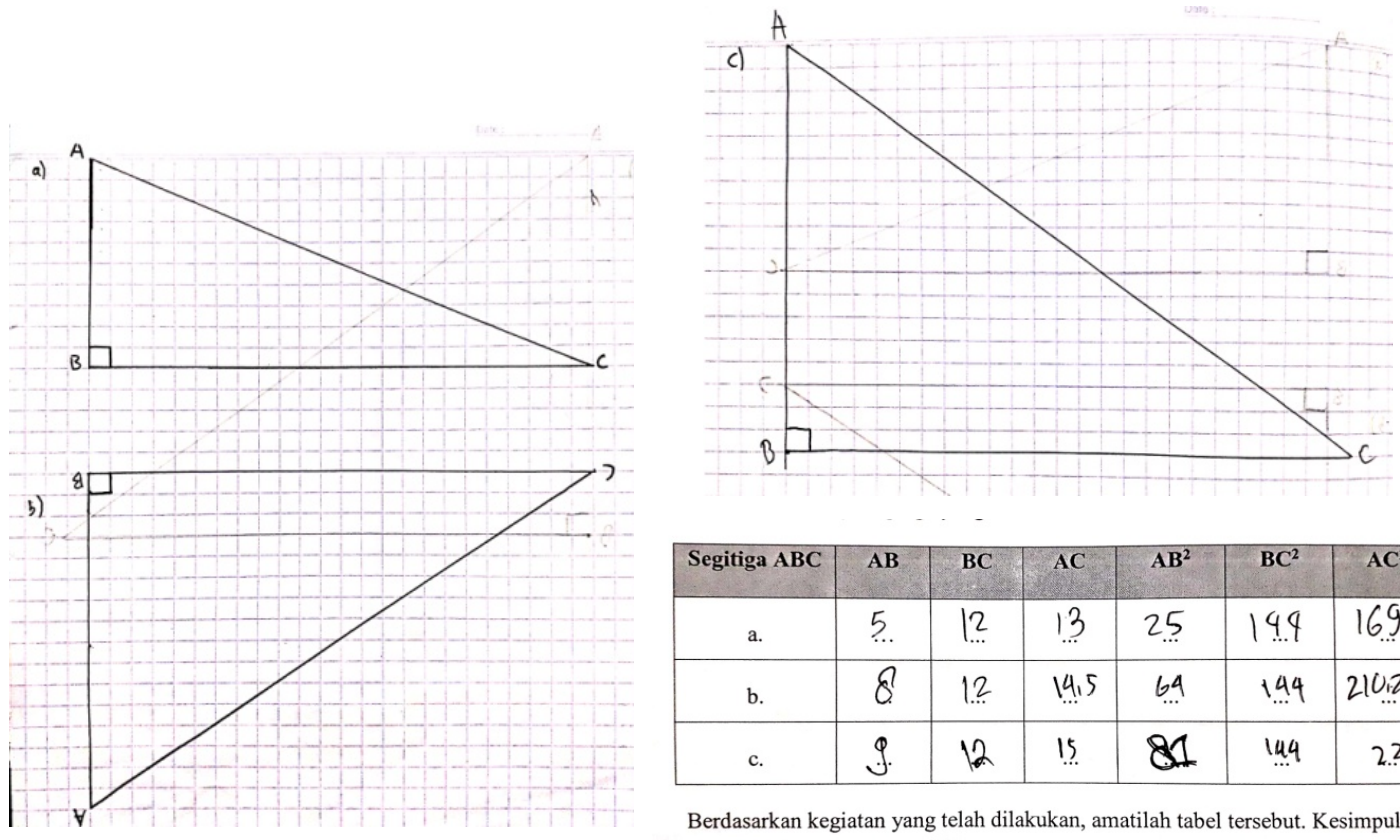

\begin{tabular}{|c|c|c|c|c|c|c|}
\hline Segitiga $\mathbf{A B C}$ & $\mathbf{A B}$ & $\mathbf{B C}$ & $\mathbf{A C}$ & $\mathbf{A B}^{2}$ & $\mathbf{B C}^{2}$ & $\mathbf{A C}^{2}$ \\
\hline a. & 5 & 12 & 13 & 25 & 149 & 169 \\
\hline b. & 8 & 12 & 14.5 & 64 & 144 & 21025 \\
\hline c. & 9 & 12 & 15 & 81 & 144 & 2.25 \\
\hline
\end{tabular}

Berdasarkan kegiatan yang telah dilakukan, amatilah tabel tersebut. Kesimpulan apa yang dapat kamu peroleh?

sisi Ac lebih Panjang dari sisi lainya

Gambar 2. Penyelesaian Kegiatan 2 Kelompok 2

\section{Memeriksa kebenaran Teorema Pythagoras menggunakan rumus}

Kegiatan ini bertujuan agar siswa dapat membuktikan secara lengkap untuk memeriksa kebenaran teorema Pythagoras melalui rumus dan gambar persegi dengan empat buah segitiga siku-siku didalamnya. Siswa diminta untuk mengisi titik-titik yang merupakan penjabaran rumus dari gambar yang tersedia.

Kelompok 4 menjawab dengan lengkap. Pada awalnya mereka bingung untuk memulainya, maka dari itu mereka aktif bertanya kepada guru dan mendengarkan penjelasan guru dengan baik, sehingga dapat melengkapi kalimat yang ada pada soal dengan benar. Aktivitas ini merupakan salah satu ciri khas dari pembelajaran guided inquiry, yang mana guru hanya berperan sebagai fasilitator selama pembelajaran yang memfasilitasi siswa dalam kegiatan bertanya selama proses pembelajaran (Rahmasantika 
\& Prahmana, 2019). Bahkan, kelompok 4 mampu menuliskan kesimpulan diakhir yang didapat, yaitu rumus teorema Pythagoras $c^{2}=a^{2}+b^{2}$, seperti tampak pada Gambar 3 .

Hasil ini memperlihatkan bahwa aktivitas diskusi dapat membimbing siswa untuk menemukan sendiri rumus teorema Pythagoras tanpa penjelasan satu arah dari guru. Aktivitas yang mampu membuat siswa menemukan sendiri suatu konsep matematis akan berdampak pada kemampuan pemahaman matematisnya (Anggraini \& Prahmana, 2018).

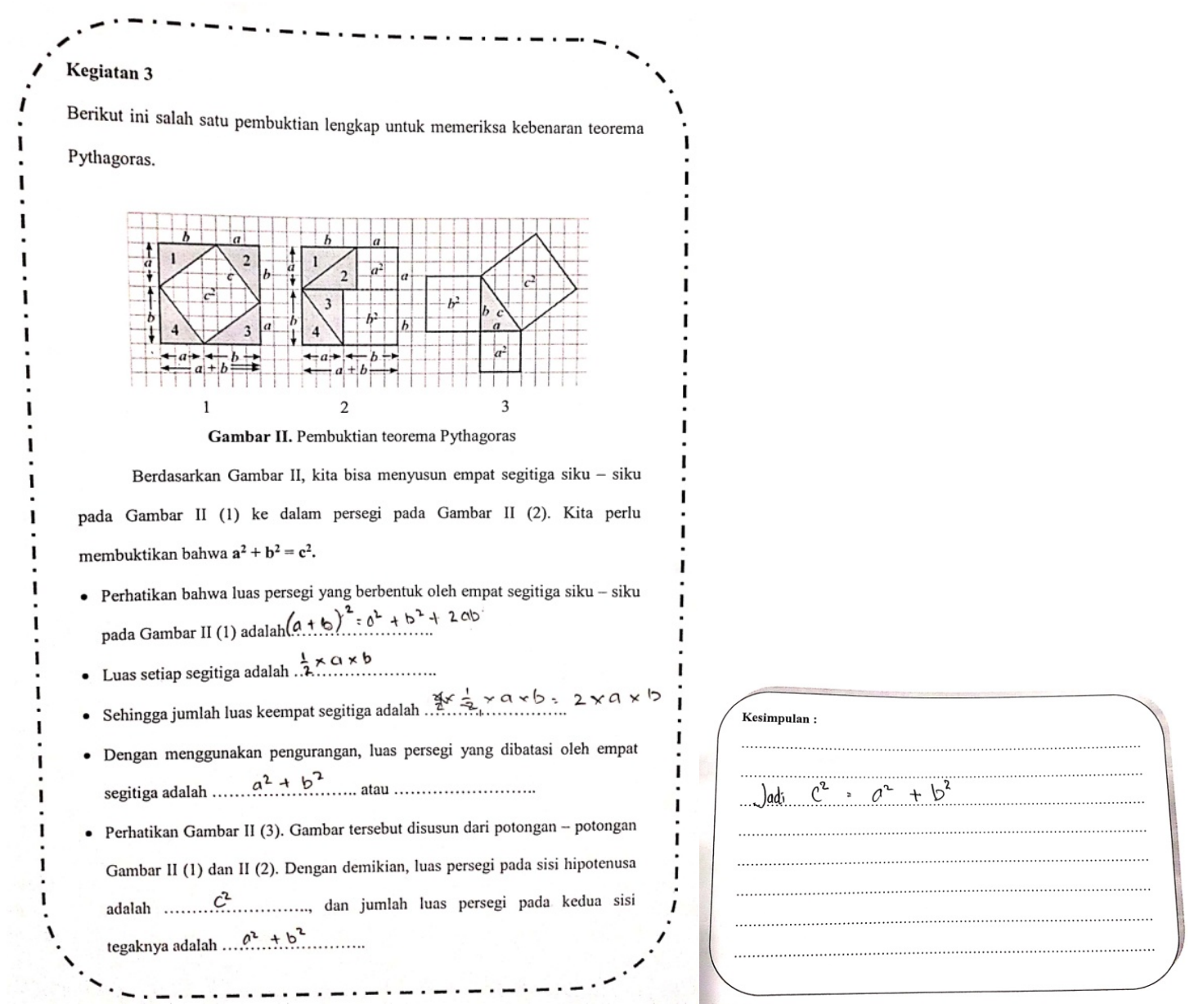

Gambar 3. Penyelesaian Kegiatan 3 Kelompok 4

\section{Menentukan panjang sisi segitiga siku-siku, jika panjang dua sisi diketahui dengan mengerjakan soal}

Kegiatan ini bertujuan untuk mengetahui apakah siswa sudah paham dengan materi yang dibahas pada kegiatan 1, kegiatan 2, dan kegiatan 3. Kegiatan 4 terdiri dari latihan soal. Sehingga, diharapkan siswa dapat mengerjakan soal evaluasi dengan baik pada pertemuan berikutnya. 
Kelompok 7 menjabarkan jawaban mereka dengan benar. Mereka menuliskan jawabannya dengan runtut dan lengkap. Pada soal nomor 1, berdasarkan ketentuan teorema Pythagoras, bahwa sisi yang ada di depan sudut siku-siku merupakan hipotenusa atau sisi miring segitiga, sehingga yang ditanyakan pada soal nomor satu yaitu panjang $\mathrm{AC}$ atau sisi miring segitiga. Rumus yang digunakan ketika mencari sisi miring segitiga, berdasarkan soal nomor 1 yaitu $\mathrm{AC}^{2}=\mathrm{AB}^{2}+\mathrm{BC}^{2}$. Hal ini dapat dilihat pada Gambar 4, bahwa kelompok 7 menuliskan rumus dengan benar. Kemudian, dilanjutkan dengan mengganti panjang $\mathrm{AB}=12$ dan $\mathrm{BC}=15$. Setelah dikuadratkan dapat diperoleh hasil yaitu $144+225=369$, sehingga panjang $\mathrm{AC}^{2}=369$ atau $\mathrm{AC}=\sqrt{369}$.

Permasalahan pada nomor 2 berbeda dengan nomor 1, karena bukan mencari sisi miring segitiga. Pada gambar diketahui bahwa tinggi segitiga yaitu $\mathrm{AB}=5 \mathrm{~cm}$ dan panjang sisi miring segitiga yaitu $A C=12 \mathrm{~cm}$. Sehingga, yang ditanyakan pada soal nomor 2 yaitu panjang alas segitiga yaitu panjang BC. Oleh karena itu, rumus yang digunakan adalah $\mathrm{BC}^{2}=\mathrm{AC}^{2}-\mathrm{AB}^{2}$. Kelompok 7 telah menuliskan rumus dengan benar. Dilanjutkan dengan perhitungan pangkat dua dari panjang $\mathrm{AC}$ dan $\mathrm{BC}$ yaitu $13^{2}$ dan $5^{2}$ menghasilkan jawaban $169-25=144$, yang mana 144 merupakan panjang $\mathrm{BC}^{2}$ maka dari itu $\mathrm{BC}=\sqrt{144}=12 \mathrm{~cm}$, seperti tampak pada Gambar 4 .

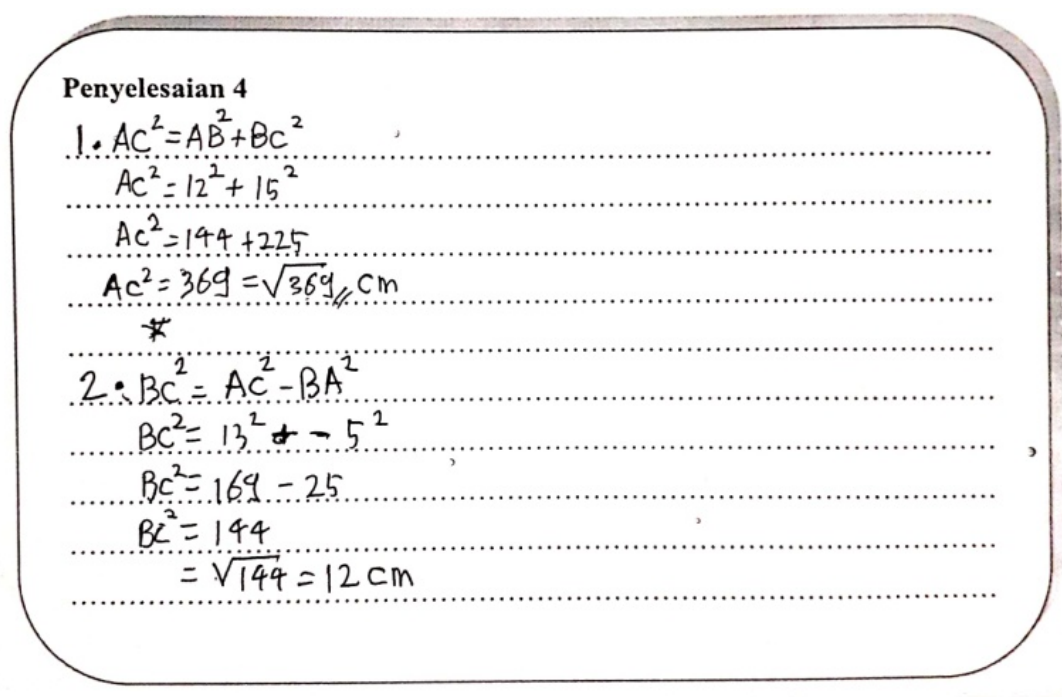

Gambar 4. Penyelesaian Kegiatan 4

\section{Menentukan jenis segitiga}

Tujuan dari kegiatan ini adalah siswa dapat menentukan jenis segitiga dengan membandingkan kuadrat sisi terpanjang dengan jumlah kuadrat kedua sisi yang lainnya. 
Jika diketahui $\triangle A B C$ dengan panjang sisi-sisinya $a, b$, dan $c$ dan diperoleh $c^{2}<a^{2}+b^{2}$, maka $\triangle A B C$ merupakan segitiga lancip di C. Sisi c dihadapan sudut siku-siku. Sedangkan jika diperoleh $c^{2}>a^{2}+b^{2}$, maka $\triangle A B C$ merupakan segitiga tumpul di C. Jika diperoleh $c^{2}$ $=a^{2}+b^{2}$, maka $\triangle A B C$ merupakan segitiga siku-siku di C, seperti tampak pada Gambar 5.

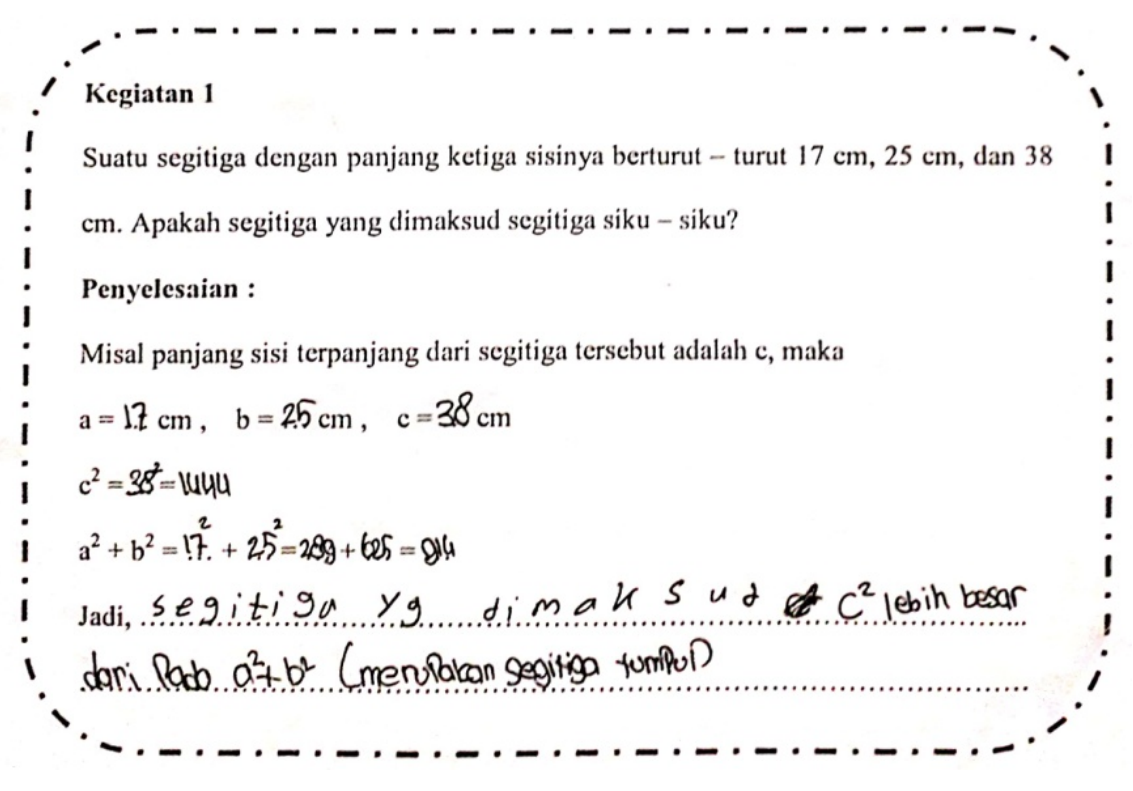

Gambar 5. Penyelesaian Kegiatan 1 Kelompok 1

Kelompok 1 mengisi sesuai petunjuk awal yaitu sisi terpanjang dari segitiga adalah c. Selanjutnya, mereka mengisi panjang c adalah $38 \mathrm{~cm}$, dikarenakan merupakan sisi paling panjang dibandingkan sisi yang lain. Kemudian, pada panjang a mereka menuliskan $17 \mathrm{~cm}$ dan panjang $\mathrm{b}$ adalah $25 \mathrm{~cm}$. Saat mengisikan $\mathrm{a}^{2}, \mathrm{~b}^{2}$ dan $\mathrm{c}^{2}$ mereka menghitung dengan benar, sehingga mereka bisa menyimpulkan dengan benar pula. Mereka menyimpulkan bahwa $\mathrm{c}^{2}$ lebih besar dari pada $a^{2}+b^{2}$ dengan begitu jenis segitiga yang dimaksud adalah segitiga tumpul.

\section{Tripel Pythagoras}

Tujuan dari kegiatan ini adalah siswa dapat mengetahui bahwa panjang sisi-sisi dari segitiga siku-siku sering kali dinyatakan dalam tiga bilangan asli. Tiga bilangan asli tersebut apabila memenuhi persamaan pada teorema pythagoras disebut triple pythagoras. Hal ini dimaksudkan siswa kedepannya dapat sekaligus menghafal bilangan yang termasuk triple Pythagoras, sehingga tidak perlu menghitung ulang dan dapat menghemat waktu.

Kelompok 5 mengerjakan dengan cermat dan teliti dalam mengisi tabel yang di minta. Walaupun beberapa kali bertanya, namun guru hanya mengarahkan dan tidak 
langsung memberikan jawabannya. Dapat dilihat pada baris ke 3 dengan $\mathrm{p}=3$ dan $\mathrm{q}=2$, mereka menuliskan jawaban pada kolom $\left(\mathrm{p}^{2}+\mathrm{q}^{2}\right)$ sesuai dengan apa yang diketahui yaitu $3^{2}+2^{2}=13$. Pada kolom $\left(\mathrm{p}^{2}-\mathrm{q}^{2}\right)$ jawaban yang mereka tulis adalah $3^{2}-2^{2}=5$. Lalu pada kolom selanjutnya yaitu 2 pq mereka menuliskan 2 × 3 × $2=12$. Mereka menghubungkan antara $\left(\mathrm{p}^{2}+\mathrm{q}^{2}\right),\left(\mathrm{p}^{2}-\mathrm{q}^{2}\right)$ dan $2 \mathrm{pq}$ dan menuliskan jawabannya pada kolom hubungan. Hubungan yang mereka tuliskan yaitu $13^{2}=5^{2}+12^{2}$, sehingga mendapatkan hasil akhir $169=169$, seperti tampak pada Gambar 6. Dikarenakan hasilnya sama, maka bilangan 13, 5, dan 12 merupakan triple pythagoras.

Jawaban pada baris 4 dan 5 mereka menjawab dengan cara yang sama dengan baris 3. Namun berbeda pada $\mathrm{p}$ dan $\mathrm{q}$ yang diketahui. Pada baris 4 , nilai $\mathrm{p}=4$ dan $\mathrm{q}=1$, sedangkan pada baris 5, nilai $\mathrm{p}=4$ dan $\mathrm{q}=2$, seperti tampak pada Gambar 6. Hubungan yang di dapat yaitu 17, 15, 8 dan 20, 16, dan 12, yang merupakan triple Pythagoras.

\begin{tabular}{|l|c|c|c|c|c|c|}
\hline$p$ & $q$ & $\left(p^{2}+q^{2}\right)$ & $\left(p^{2}-q^{2}\right)$ & $2 p q$ & Hubungan & $\begin{array}{c}\text { Triple } \\
\text { Pythagoras }\end{array}$ \\
\hline 2 & 1 & $2^{2}+1^{2}=5$ & $2^{2}-1^{2}=3$ & $2 \times 2 \times 1=4$ & $\begin{array}{l}5^{2}=3^{2}+4^{2} \\
25=9+16 \\
25=25\end{array}$ & $5,3,4$ \\
\hline 3 & 1 & $3^{2}+1^{2}=10$ & $3^{2}-1^{2}=8$ & $2 \times 3 \times 1=6$ & $\begin{array}{l}10^{2}=8^{2}+6^{2} \\
100=64+36 \\
100=100\end{array}$ & $10,8,6$ \\
\hline 3 & 2 & $3^{2}+2^{2}=13$ & $3^{2}-2^{2}=5$ & $2 \times 3 \times 2=12$ & $\begin{array}{l}13^{2}=5^{2}+12^{2} \\
169=25+144 \\
169=169\end{array}$ & $13,5,12$ \\
\hline 4 & 1 & $4^{2}+1^{2}=17$ & $4^{2}-1^{2}=15$ & $2 \times 4 \times 1=8$ & $\begin{array}{l}1 \\
17^{2}=15^{2}+8^{2} \\
289=255+64^{\prime} \\
289=289\end{array}$ & 17,1518 \\
\hline 4 & 2 & $4^{2}+2^{2}=20$ & $4^{2}-2^{2}=12$ & $2 \times 4 \times 2=16$ & $\begin{array}{l}200^{2}=12^{2}+16^{2} \\
400=144+256 \\
400=400\end{array}$ & $26,12,16$ \\
\hline
\end{tabular}

Gambar 6. Penyelesaian Kegiatan 2 Kelompok 5

\section{Penyelesaian soal jenis segitiga dan tripel Pythagoras}

Tujuan dari kegiatan ini adalah untuk mengetahui apakah siswa sudah paham dengan materi yang dibahas pada kegiatan 1 dan kegiatan 2. Sehingga, diharapkan siswa dapat mengerjakan soal evaluasi dengan baik pada pertemuan berikutnya.

Kelompok 6 berhasil mengerjakan nomor 1 dengan lengkap. Mereka menyatakan bahwa nomor 1.a merupakan segitiga lancip karena $\mathrm{a}^{2}+\mathrm{b}^{2}>\mathrm{c}^{2}$. Selanjutnya, untuk nomor 
1.b merupakan segitiga siku-siku karena $\mathrm{a}^{2}+\mathrm{b}^{2}=\mathrm{c}^{2}$. Dan yang terakhir merupakan segitiga tumpul karena $\mathrm{a}^{2}+\mathrm{b}^{2}<\mathrm{c}^{2}$, seperti tampak pada Gambar 7 .

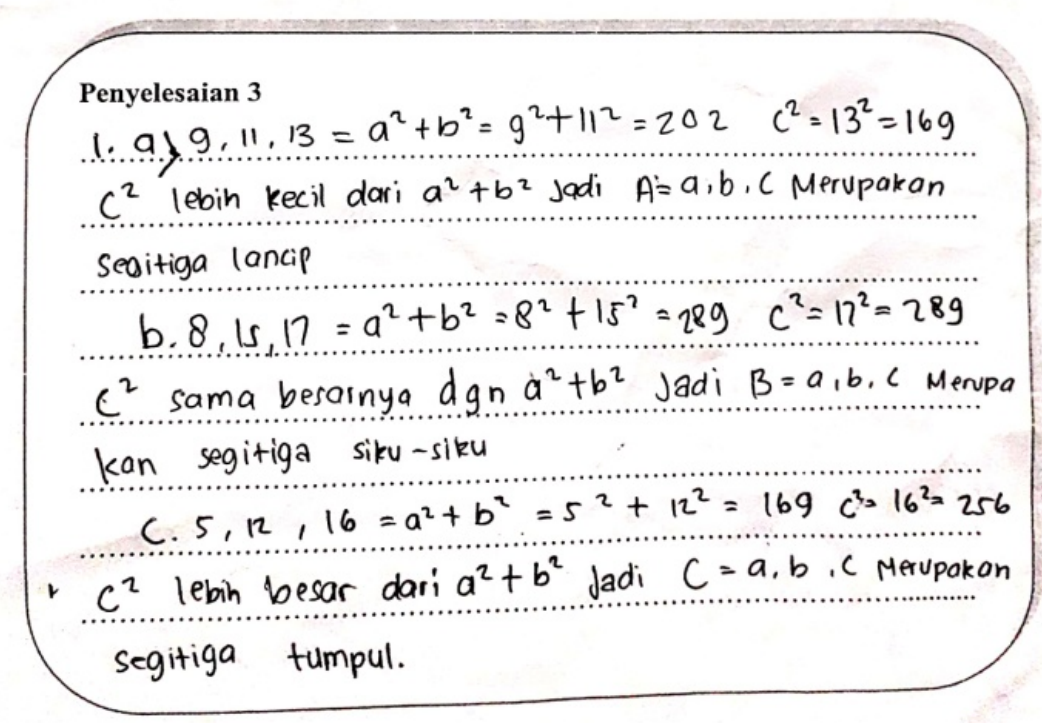

Gambar 7. Penyelesaian Kegiatan 3 oleh Kelompok 6

Dengan menggunakan model pembelajaran guided inquiry, siswa dapat membuktikan rumus teorema Pythagoras dan memahami konsep teorema Pythagoras dengan melakukan sejumlah kegiatan yang telah dirancang. Hal ini sejalan dengan penelitian sejumlah peneliti yang menghasilkan besaran rata-rata peningkatan kemampuan pemahaman konsep matematis antara siswa yang menggunakan metode Guided Inquiry lebih tinggi dibandingkan dengan siswa yang menggunakan metode pembelajaran secara konvensional (Badjeber \& Fatimah, 2015; Mawaddah \& Maryanti, 2016; Murnaka \& Dewi, 2018). Selanjutnya, rumus teorema Pythagoras yang diperoleh siswa melalui aktivitas pembelajaran ini adalah sisi miring dikuadratkan sama dengan jumlah kuadrat dari dua sisi yang lainnya. Melalui rumus Pythagoras yang diperoleh, siswa dapat menentukan jenis segitiga dan triple Pythagoras.

Pada akhir pembelajaran, diberikan soal evaluasi berdasarkan materi yang diberikan pada kegiatan belajar-mengajar. Soal evaluasi ini digunakan untuk mengetahui pemahaman siswa terharap materi yang telah diberikan. Hasil evaluasi siswa setelah diterapkan model pembelajaran Guided Inquiry pada materi teorema Pythagoras menunjukkan bahwa rata-rata score yang diperoleh siswa adalah 66,1 dengan Kriteria Ketuntasan Minimal (KKM) sebesar 65. Ini artinya, nilai rata-rata siswa di atas nilai KKM yang ditetapkan oleh sekolah. 
Selanjutnya, sebanyak 19 dari 32 siswa yang hadir nilainya di atas KKM. Perolehan nilai tertinggi siswa adalah 96, sedangkan perolehan nilai terendah adalah 29.

\section{KESIMPULAN}

Pembelajaran teorema pythagoras melalui Lembar Aktivitas Siswa (LAS) model pembelajaran Guided Inquiry, guru membimbing siswa untuk menemukan konsep teorema pythagoras melalui kegiatan inkuiri dengan jalan mengajukan pertanyaan-pertanyaan awal dan mengarahkan siswa pada suatu diskusi. Proses inkuiri dilakukan melalui tuntunan LAS yang rinci, yang mana pada setiap tahapan terdapat petunjuk atau pedoman yang dirancang oleh guru, sehingga dapat menuntun siswa untuk menemukan konsep teorema phytagoras yang menjadi target pembelajaran. Kemampuan pemahaman konsep siswa pada materi teorema Pythagoras menggunakan model pembelajaran guided inquiry dapat berhasil dilakukan pada siswa yang aktif. Siswa mampu memahami konsep teorema Pythagoras dengan melakukan berbagai kegiatan pada model pembelajaran guided inquiry.

\section{DAFTAR PUSTAKA}

Akbar, M. Z. I., Rohaeti, E. E., \& Senjayawati, E. (2019). Efektifitas lembar kegiatan siswa berbasis pendekatan CTL pada materi teorema Pythagoras untuk siswa SMP. Journal on Education, 1(2), 142-150.

Anggraini, P., \& Prahmana, R. C. I. (2018). Analisis kemampuan pemahaman matematis pada materi bentuk pangkat, akar, dan logaritma di SMK. Journal of Honai Math, 1(1), 1-13.

Badjeber, R., \& Fatimah, S. (2015). Peningkatan kemampuan koneksi matematis siswa SMP melalui pembelajaran inkuiri model alberta. Jurnal Pengajaran MIPA, 20(1), 18-26.

Gunur, B., Lalus, E., \& Ali, F. A. (2019). Students' Understanding Of Mathematical Concepts Through The Guided Inquiry Learning. Edumatica: Jurnal Pendidikan Matematika, 9(02), 34-40.

Hendriana, H. (2014). Membangun kepercayaan diri siswa melalui pembelajaran matematika humanis. Jurnal Pengajaran MIPA, 19(1), 52-60.

Lestari, K. E. (2015). Penerapan model pembelajaran M-Apos untuk meningkatkan kemampuan pemecahan masalah matematis siswa SMP. Jurnal Pendidikan UNSIKA, 3(1), 45-52. 
Masjudin, M. (2017). Pembelajaran kooperatif investigatif untuk meningkatkan pemahaman siswa materi barisan dan deret. Jurnal Edukasi Matematika dan Sains, 4(2), 76-84.

Mawaddah, S., \& Maryanti, R. (2016). Kemampuan pemahaman konsep matematis siswa SMP dalam pembelajaran menggunakan model penemuan terbimbing (discovery learning). EDU-MAT, 4(1), 76-85.

Murnaka, N. P., \& Dewi, S. R. (2018). Penerapan metode pembelajaran Guided Inquiry untuk meningkatkan kemampuan pemahaman konsep matematis. Journal of Medives: Journal of Mathematics Education IKIP Veteran Semarang, 2(2), 163-171.

Peraturan Menteri Pendidikan dan Kebudayaan Nomor 24 Tahun 2016.

Pratiwi, D. D. (2016). Pembelajaran learning cycle 5E berbantuan geogebra terhadap kemampuan pemahaman konsep matematis. Al-Jabar: Jurnal Pendidikan Matematika, 7(2), 191-202.

Purwanti, R. D., Pratiwi, D. D., \& Rinaldi, A. (2016). Pengaruh Pembelajaran Berbatuan Geogebra terhadap Pemahaman Konsep Matematis ditinjau dari Gaya Kognitif. AlJabar: Jurnal Pendidikan Matematika, 7(1), 115-122.

Rahma, A. (2019). Pengaruh penggunaan model pembelajaran Problem Based Instruction (PBI) terhadap kemampuan pemecahan masalah matematika materi teorema Pythagoras di kelas VIII SMP Negeri 1 Padang Bolak Julu. Jurnal MathEdu, 2(1), 1-6.

Rahmasantika, D., \& Prahmana, R. C. I. (2019). Desain pembelajaran perbandingan senilai menggunakan Guided Inquiry. Journal of Honai Math, 2(2), 85-102.

Ramadhani, A., \& Prahmana, R. C. I. (2019). Desain pembelajaran garis dan sudut menggunakan jam dinding lingkaran untuk siswa SMP kelas VII. Jurnal Review Pembelajaran Matematika, 4(2), 85-101.

Ulfah, A. F., \& Prahmana, R. C. I. (2018). Single subject research: Implementasi pembelajaran berbasis masalah terhadap pemahaman matematis siswa. Jurnal Elemen, 4(1), 105-118.

Zamnah, L. N., \& Ruswana, A. M. (2018). Meningkatkan Kemampuan Pemahaman Matematis dan Self-Confidence melalui Pembelajaran Peer Instruction With Structured Inquiry (PISI).JPPM (Jurnal Penelitian dan Pembelajaran Matematika), 11(1), 49-62. 